\title{
Influence of the shape of hydrogen-containing inclusions on the intergranular corrosion process of the Al - Si alloy system
}

\author{
E. G. Partyko, Assistant, Foundry Department ${ }^{1}$, e-mail: elforion@mail.ru \\ V. B. Deev, Professor, Department of Foundry Technology ${ }^{2}$, e-mail: deev.vb@mail.ru \\ M. I. Gubanova, Post-Graduate Student, Foundry Department ${ }^{1}$, e-mail: g-m-i@mail.ru \\ ${ }^{1}$ Siberian Federal University, Krasnoyarsk, Russia. \\ ${ }^{2}$ National University of Science and Technology "MISiS", Moscow, Russia.
}

D. V. Tolkachyova, Post-Graduate Student, Foundry Department ${ }^{1}$, e-mail: D.Tolkacheva@krastsvetmet.ru

\begin{abstract}
It is known that the surface of aluminum alloys is characterized by the formation of pitting (point damage), which can subsequently cause intergranular corrosion. This corrosion damage is dangerous in that it is almost impossible to detect it visually, since it extends from surface into interior of the material. The effect of the form of hydrogen inclusions on the corrosion resistance of an $\mathrm{Al}-\mathrm{Si}$ alloy is investigated. For the tests on intergranular corrosion were selected uncoated samples of silumin AK12 (ENAC-AISi12(a), A04130) with different forms of hydrogen inclusions - atomic and molecular. The content of dissolved hydrogen in all samples is $0.2 \mathrm{~cm}^{3} / 100 \mathrm{~g}$. The duration of methodical tests in special solution of sodium chloride $(\mathrm{NaCl})$ and hydrochloric acid $(\mathrm{HCl})$ is 24 hours. Additionally, two samples from each series were exposed to a solution of another 48 hours. Evaluation of the effects of intergranular corrosion on silumin samples was performed by metallographic method. Given the fact that the data on the loss of mass over a certain period of time are less reliable, in comparison with the data on the structure change over the same time Then, the effect of intergranular corrosion on the mechanical properties of silumin was evaluated using the electromechanical universal testing machine. During the research was found that at the equal content of the dissolved hydrogen samples with molecular inclusions are more subject to intergranular destruction. This follows from the considerable depth of corrosion propagation and the decrease in the mechanical properties of silumin relative to the results for samples with atomic hydrogen. Wherein the analysis of the level of mechanical properties showed that after intergranular corrosion, the tensile strain decreases to a considerable extent.
\end{abstract}

Key words: hydrogen, aluminum alloy, silumin, corrosion, mechanical properties.

DOI: $10.17580 / \mathrm{nfm} .2018 .02 .03$

\section{Introduction}

A luminum and its alloys find wide application in various branches of modern industry (space, aviation, automotive, instrumental, etc.), which impose special requirements to the used structural materials. Consequently, the study of the influence of corrosion processes on the mechanical and operational properties of aluminum-based alloys is an actual scientific and technical task.

Castings and parts from aluminum alloys have a relatively high corrosion resistance due to the presence on the surface of an inert oxide film. At the same time, the impact of various environmental factors leads to the thinning of the upper layer of natural oxide protection. Moisture accumulating on the surface of the metal as a result of pre- cipitation of dew or atmospheric precipitation initiates the course of electrochemical reactions, which may result in nucleation of corrosion spot, destruction and decrease in the safety of products [1-2].

Reduction of water containing leads to the emission of hydrogen. That is a key cathodic process for corrosion of many metals. Hydrogen emission occurs locally where the naturally formed oxide is disrupted. The presence of cathodically active alloying elements enhances superfluous hydrogen emission response to either anodic or cathodic polarisation and results in "cathodic activation" of the dissolved regions during corrosion process [3].

The surface of aluminum alloys is characterized by the formation of pitting (point damage), which can subsequently cause intergranular corrosion. This corrosion 
damage is dangerous in that it is almost impossible to detect it visually, since it extends from surface into interior of the material. Tracking the development of intergranular corrosion in full-scale climatic conditions requires longterm testing - from 2 to 10 years, depending on aggressiveness of environment.

Today, there are two schemes of nucleation and development of intergranular corrosion process [4]. The first corresponds to alloys in the structure of which there are no continuous anode paths and there are only discrete cathode sections (groups of intermetallic compounds) located near the grain boundaries. The appearance of damage centers in this case is connected with the energy state of grain boundaries, the cathode effect of intermetallic compounds and the presence of voids formed due to coagulation of vacancies. Further development of pitting occurs on the tunnel mechanism along the boundaries, near cathode phases, through voids and anodic phases. Corrosive environment in microtunnels acidified, so is their expansion and consolidation into larger formations. It begins continuous spread of corrosion at the grain boundaries. Thus, nucleation of the center of corrosion is caused by a violation of the passive state of material, and its development by changing the composition of medium at top of the pitting.

The second scheme is applicable to alloys having continuous anodic sections along grain boundaries in the form of a $\beta$-phase, which has been released as a continuous film. Here the grouping of cathode trace elements at grain boundaries or near them is an optional condition. Nevertheless, the matrix should be a sufficiently effective cathode with respect to the released phase.

In the general case, the following factors influence the occurrence of intergranular corrosion:

- the nature of metal or alloy (aluminum, nickel, zinc apt to formation of pittings; molybdenum, chrome is not affected);

- temperature (with temperature increase the number of pittings grows);

- surface condition (roughness reduce firmness of material);

$-\mathrm{pH}$ (pittings arise in acidic environments more of ten);

- impurity in the environment (ions activators of $\mathrm{Cl}^{-}$, $\left.\mathrm{Br}^{-}, \mathrm{J}^{-}\right)$;

- vital activity of microorganisms biodestructors.

In this case, aluminum alloys with a high concentration of alloying elements are more susceptible to corrosion destruction than alloys with a low degree of supersaturation of solid solution. One of the main prerequisites for such destruction is the presence of hydrogen inclusions [5-12].

From the foregoing follows validity of purpose of this research, namely, determination of the influence of the form of hydrogen inclusions on corrosion processes in aluminum alloys on the example of silumin AK12 (analog in Europe - ENAC-AlSi12(a), in USA - A04130).

\section{Methods}

Samples for research were made by low-pressure casting from AK12 alloy (Table 1). This method of casting was chosen with the aim of forming zones with different forms of hydrogen in castings. Formation of the structure in different zones of casting was carried out under conditions of controlled forced cooling by air.

For the tests on intergranular corrosion were selected and marked 10 uncoated samples of silumin with different forms of hydrogen inclusions - atomic and molecular. The presence of a certain form of hydrogen inclusions in the samples was confirmed with the EVO50 electron scanning microscope. The sample size is $20 \times 10 \times 5 \mathrm{~mm}$.

The content of dissolved hydrogen in experimental alloy was determined on the device AV-1 (analyzer of hydrogen in aluminum alloys). This equipment is a specialized highsensitivity magnetic mass spectrometer tuned for hydrogen registration, equipped with a digital recording system for mathematical processing of measurement results and an extraction and charging unit for high-temperature vacuum extraction of hydrogen from aluminum samples. The principle of the device is based on measuring the amount of hydrogen extracted from a sample when it is heated to a temperature close to the melting point (vacuum heating), or when the sample is melted in vacuum (vacuum-melting).

In the samples prepared for the study, regardless of the form of the inclusions, the hydrogen content is $0.2 \mathrm{~cm}^{3} / 100 \mathrm{~g}$.

Before and after the intergranular corrosion tests, samples were weighed on analytical scales with an accuracy of $10^{-5} \mathrm{~g}$. Also, the preparation of the samples consisted of degreasing them with an organic solvent (acetone), followed by drying with filter paper.

Tests were carried out in glass containers. The samples were immersed in a thoroughly mixed solution containing $3 \%$ sodium chloride $(\mathrm{NaCl})$ plus $1 \%$ hydrochloric acid $(\mathrm{HCl})$ at a temperature of $18-25^{\circ} \mathrm{C}$. Separate immersion of the samples in individual containers has allowed to avoid their contact with each other and the imposition of additional effects of electrolytic corrosion. The solution level above the upper edge of each of them was $20 \mathrm{~mm}$.

The duration of methodical tests is 24 hours. Additionally, two samples from each series were exposed to a solution of another 48 hours. At the end of the tests in the solution, the samples were washed with flowing and distilled water, then dried at a temperature of $100 \pm 5{ }^{\circ} \mathrm{C}$ for 5 minutes.

\begin{tabular}{|l|c|c|c|c|c|c|c|c|c|c|}
\hline Element & $\mathrm{Fe}$ & $\mathrm{Si}$ & $\mathrm{Mn}$ & $\mathrm{Ti}$ & $\mathrm{Cu}$ & $\mathrm{Zr}$ & $\mathrm{Mg}$ & $\mathrm{Zn}$ & $\mathrm{Al}$ & Impurities \\
\hline Containing, \% & 0.3 & 12 & 0.3 & 0.05 & 0.3 & 0.05 & 0.05 & 0.2 & balance & 2.7 \\
\hline
\end{tabular}


Table 2

Technical characteristics of the testing machine WDW-10

\begin{tabular}{|l|l|}
\hline Maximum load, $\mathrm{kN}$ & 10 \\
\hline Stiffness of the power frame, $\mathrm{kN} / \mathrm{mm}$ & 80 \\
\hline Load accuracy, \% & \pm 1 \\
\hline Load range, \% & $0.4-100$ \\
\hline Deformation range, \% & $2-100$ \\
\hline Deformation accuracy, \% & \pm 1 \\
\hline Travel resolution, mm & 0,001 \\
\hline Accuracy of movement, \% & \pm 1 \\
\hline Range of loading speeds, $\mathrm{mm} / \mathrm{min}$ & $0.005-500$ \\
\hline
\end{tabular}

Evaluation of the effects of intergranular corrosion on silumin samples was performed by metallographic method using the OLYMPUS GX51 microscope less than 7 days after the tests. The maximum depth of intergranular corrosion (in microns) and its propagation along the edge of the sample were recorded.
In addition, cylindrical samples were held in the test solution for 24 hours. Then, the effect of intergranular corrosion on the mechanical properties of silumin was evaluated using the electromechanical universal testing machine WDW 10 (Table 2). This equipment is used for static testing of tensile, compression and bending of nonmetallic materials, as well as testing of non-ferrous metals with small strength parameters.

Software WinWDW, developed by the specialists of TIME Group Inc. for this testing machine, allows to adjust parameters in accordance with the main international, European, American and Russian standards: ISO 6892-84, ASTM E8, DIN 50125, EN 10002, State Standart 1497-84.

\section{Results}

Intergranular corrosion destruction is dangerous in that it extends from the surface into the interior of the material. Figures 1 and 2 (one point of the background grid
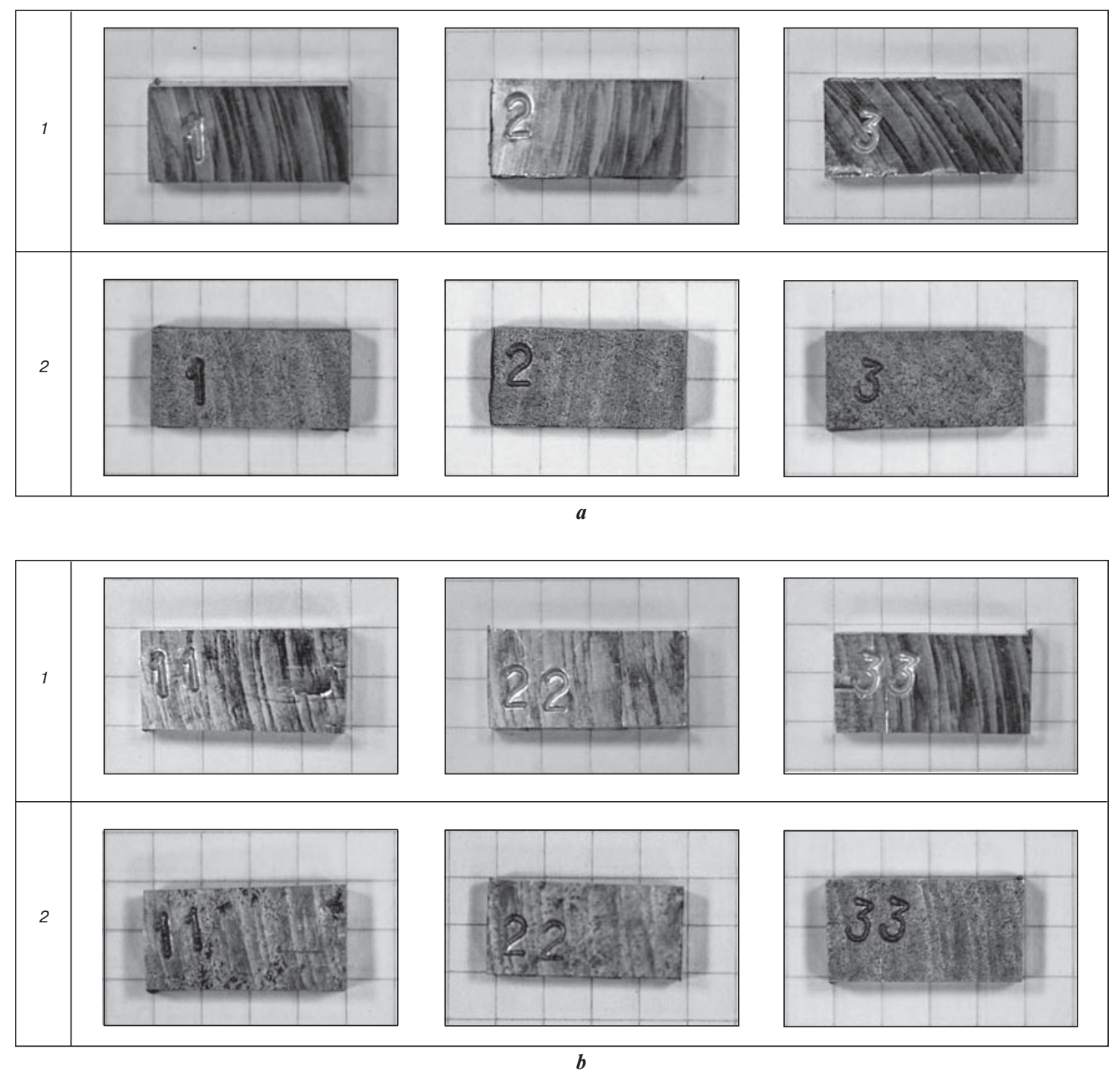

Fig. 1. Exterior view of samples with atomic $(a)$ and molecular $(b)$ form of hydrogen inclusions: 1 - before test; 2 - after testing for $24 \mathrm{~h}$. 
amount to $5 \mathrm{~mm}$ ) show the effect of intergranular corrosion on selected samples of silumin, leading to a change in their exterior view and mass.

In this case, the data on the loss of mass over a certain period of time are less reliable, in comparison with
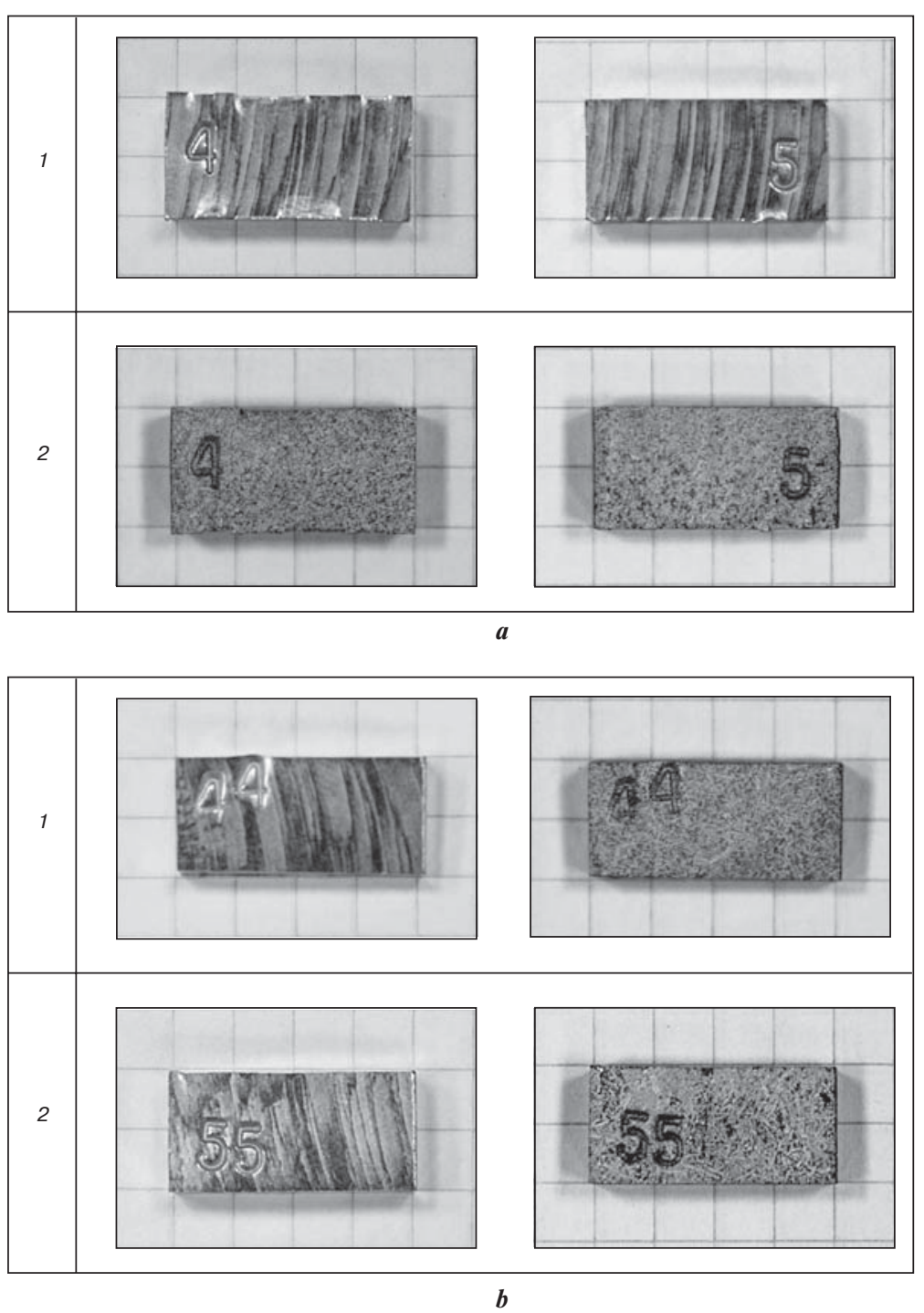

Fig. 2. Exterior view of samples with atomic $(a)$ and molecular $(b)$ form of hydrogen inclusions:

1 - before test; 2 - after testing for $72 \mathrm{~h}$ the data on the structure change over the same time (Fig. 3). Nevertheless, it was shown that the change in mass for samples with atomic hydrogen form in 24 hours was $0.0132 \mathrm{~g}$, for 72 hours $-0.025 \mathrm{~g}$. Whereas for samples with a molecular hydrogen form in 24 hours it was $0.0248 \mathrm{~g}$, for $72 \mathrm{~h}-0.269 \mathrm{~g}$. This is explained by the fact that in samples with a molecular form of hydrogen inclusions, the area of interaction with the solution is greater due to hydrogen porosity.

In intergranular corrosion only, certain structural components are irritated. The specific features of intergranular corrosion can differ only in metallographic studies, so the change in the structural state over fixed time intervals has been studied. The results of the metallographic study are shown in Fig. 4.

Fig. $4, b$ shows that corrosion begins and spreads from the pores, developing along intermetallic inclusions located along the grain boundaries. This is due to the fact that during the contact of the corrosive medium with the metal, the existing potential difference between the discharge along the boundaries of the dendritic cells and the edge of the dendrites increases. Depending on the degree of inertness of these precipitates in relation to the base metal, they either influence the dissolution process along the boundaries of the dendritic cells (Fig. 4, b) or dissolve themselves (Fig. 4, $a$ ). In both cases, there is a certain loss of connection between the individual crystallites. As a result, the metal loses strength and plasticity over time.

A study of the structure of samples showed that in the course of experiment the development of intergranular corrosion is more pronounced in samples with a molecular form of hydrogen. The average depth of intergranular corrosion for
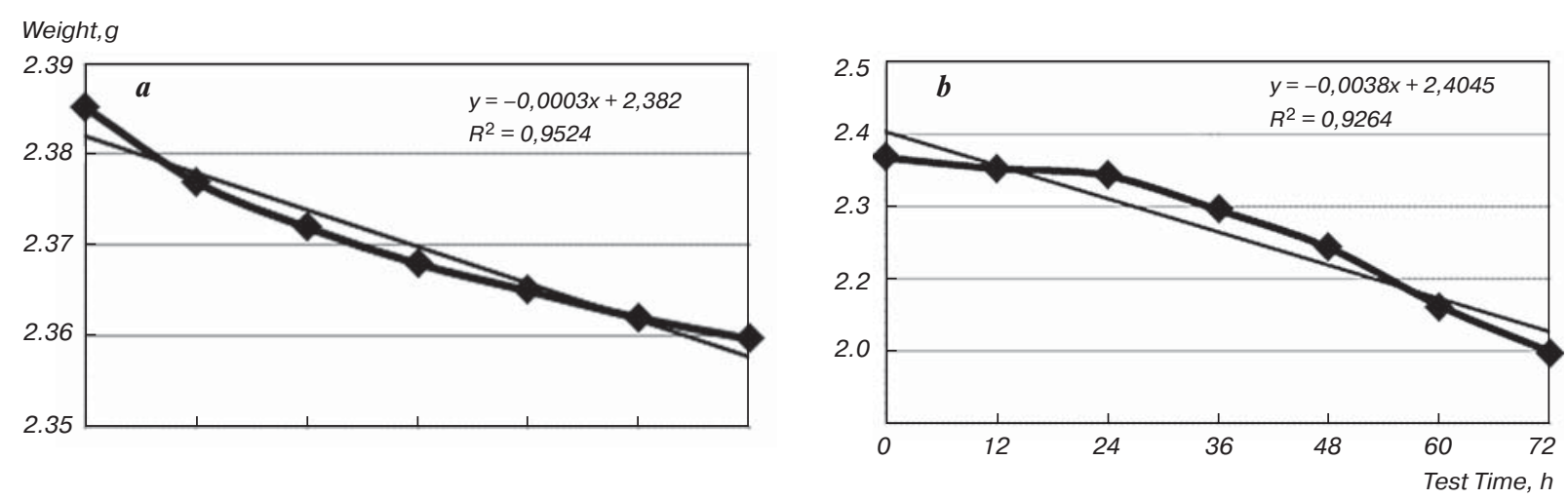

Fig. 3. Changes in the mass of samples with atomic $(a)$ and molecular $(b)$ forms of hydrogen inclusions during the tests 

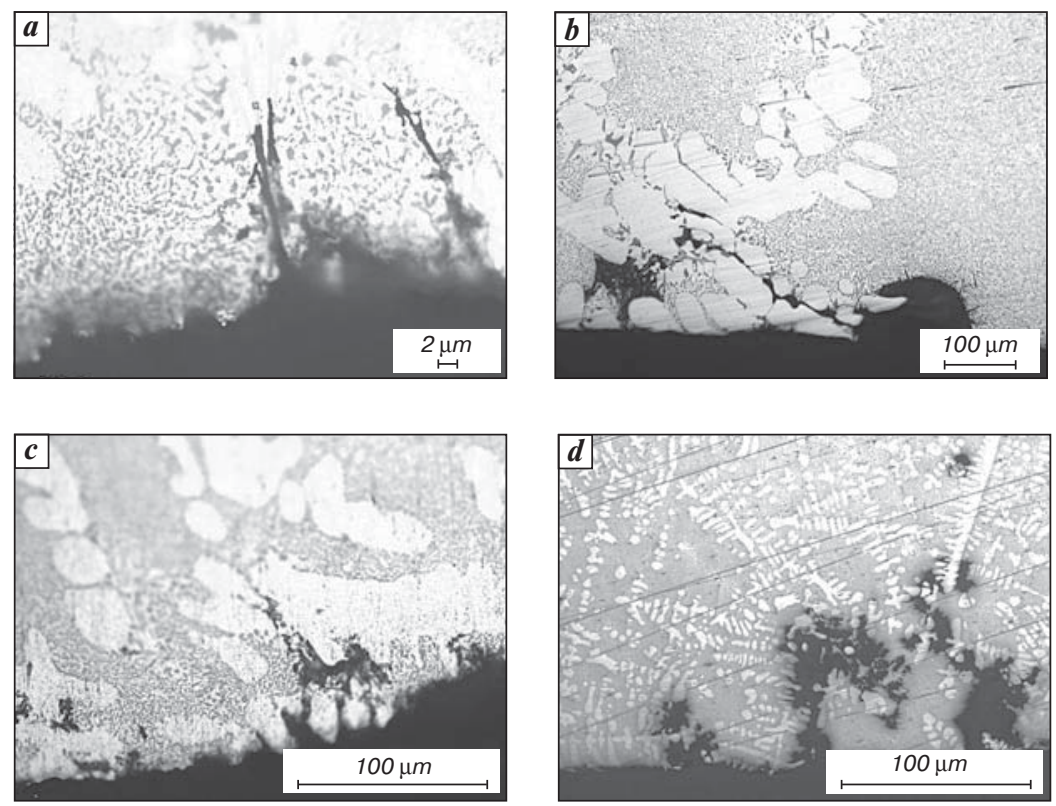

Fig. 4. Microstructure of silumin samples after corrosion: $a, c$-hydrogen in atomic form; $b, d$-hydrogen in molecular form; $a, d$ - test $24 \mathrm{~h} ; c, b-$ test $72 \mathrm{~h}$
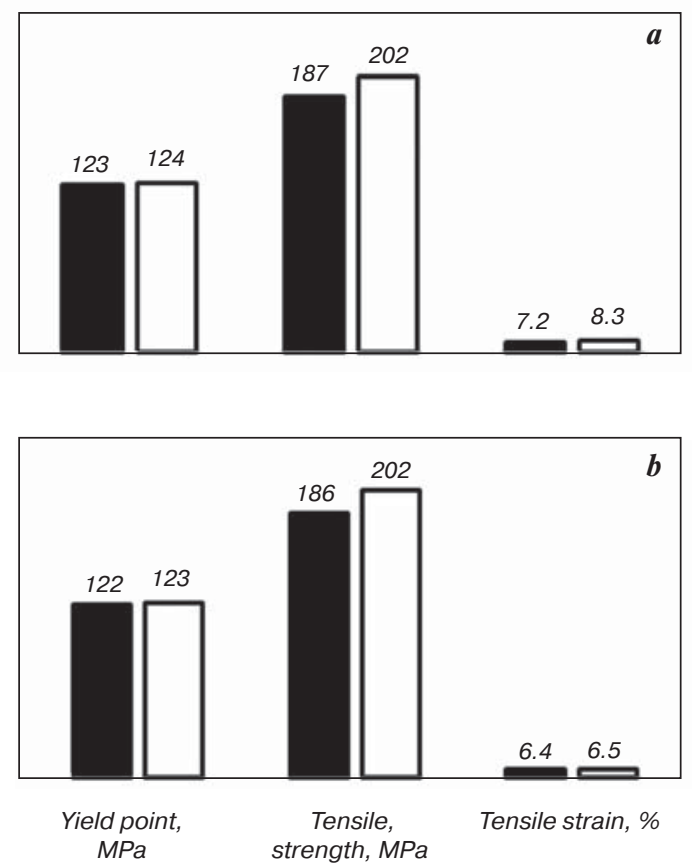

Fig. 5. Mechanical properties of cylindrical silumin samples: $a$ - hydrogen in atomic form; $b$ - hydrogen in molecular form; $\square-$ before corrosion test; $\square-$ after corrosion test

samples with atomic and molecular forms of hydrogen inclusions was, respectively:

- 27 and 361 microns after 24 hours in test solution;

- 44 and 1215 microns after 72 hours in test solution.

The test results of mechanical properties for cylindrical samples are shown in Fig. 5.

Analysis of the level of mechanical properties showed that after intergranular corrosion, the tensile strain decreases to a considerable extent. It is noted that the tensile strain of the initial samples with the molecular form of hydrogen inclusions is $21 \%$ lower in comparison for samples with an atomic form of hydrogen inclusions. This is explained by the presence in the structure of gas pores with a size of $100 \div 200 \mu \mathrm{m}$. The formation of structure defects during the tests led to a further decrease the tensile strain in samples with the molecular form of hydrogen by an average of $28 \%$.

\section{Conclusion}

Thus, by the metallographic method has revealed that the depth of propagation of intergranular corrosion in silumin castings is influenced not by the hydrogen content of the alloy, but by its shape. The predominant presence of hydrogen in the molecular form promotes the development of corrosion processes and a reduction in the service characteristics of aluminum alloy structures.

For decrease in negative effect of molecular hydrogenous inclusions it is recommended to provide control of cast technology, choose the hydrodynamic and thermal modes of casting providing the optimum crystallization speed of casting.

The work was carried out within the project 14.578.21.0193 "Development of theoretical and technological solutions for hydrogen reduction in aluminum and lowalloyed aluminum alloys" of the Federal Target Program "Researches and developments in the priority directions of progress of Scientific and Technological Complex of Russia for 2014-2020" with the financial support of the Ministry of Education and Science of the Russian Federation. The unique identifier of agreement RFMEFI57816X0193.

\section{References}

1. Joseph R. Davis (Ed.). Corrosion of Aluminum and Aluminum Alloys. Ohio : ASM International, 1999. $313 \mathrm{p}$.

2. Bogdanova T. A., Dovzhenko N. N., Babkin V. G., Zhereb V. P., Merkulova A. V. et al. Structure formation of aluminum casting alloy for casting under low-pressure. Krasnoyarsk : Sibirskiy Fedederalniy Universitet, 2015. 164 p.

3. Laurent C., Scenini F., Monetta T., Bellucci F., Curioni M. The contribution of hydrogen evolution processes during corrosion of aluminium and aluminium alloys investigated by potentiodynamic polarisation coupled with real-time hydrogen measurement. npj Materials Degradation. 2017. Vol. 1, Iss. 1. DOI: 10.1038/s41529-017-0011-4.

4. Kablov E. N., Startsev O. V., Medvedev I. M. Review of international experience on corrosion and corrosion protection. J. Aviation Materials and Technologies. 2015. No. 2. pp. 76-87. 
5. Lunarska E., Chernyaeva O. Effect of precipitates on hydrogen transport and hydrogen embrittlement of aluminum alloys. Materials Science. 2004. Vol. 40, Iss. 3. pp. 399-407.

6. Kim S. J., Han M. S., Jang S. K. Electrochemical characteristics of $\mathrm{Al}-\mathrm{Mg}$ alloy in seawater for leisure ship: Stress corrosion cracking and hydrogen embrittlement. Korean Journal of Chemical Engineering. 2009. Vol. 26, Iss. 1. pp. 250-257.

7. Kumar S., Namboodhiri T., Precipitation hardening and hydrogen embrittlement of aluminum alloy AA7020. Bulletin of Materials Science. 2011. Vol. 34, Iss. 2. pp. 311-321.

8. Belyaev S. V., Kulikov B. P., Deev V. B., Baranov V. N., Rakhuba E. M. Analysis of Hydrogen Content in the Main Stages of Low-Alloy Aluminum Alloy Flat Ingot Manufacture. Metallurgist. 2017. Vol. 61, Iss. 3-4. pp. 325-329.

9. Bazhin V. Yu., Sizyakov V. M., Vlasov A. A., Feshchenko R. Yu. Surface defects in foil direct chill strip from highly- alloyed aluminum alloys. Metallurgist. 2013. Vol. 56, Iss. 11-12. pp. 863-866.

10. Deev V. B., Ponomareva K. V., Yudin A. S. Investigation into the density of polystyrene foam models when implementing the resource-saving fabrication technology of thin-wall aluminum sheet. Russian Journal of Non-Ferrous Metals. 2015. Vol. 56, Iss. 3. pp. 283-286.

11. Deev V. B., Selyanin I. F., Ponomareva K. V., Yudin A. S., Tsetsorina S. A. Fast cooling of aluminum alloys in casting with a gasifying core. Steel in Translation. 2014. Vol. 44, Iss. 4. pp. 254-254.

12. Kolonakov A. A., Kukharenko A. V., Deev V. B., Abaturova A. A. Structure and chemical composition of the AK$12 \mathrm{MMgN}$ piston alloy fabricated based on various charges. Russian Journal of Non-Ferrous Metals. 2015. Vol. 56, Iss. 4. pp. 428-433.

\title{
Investigation of the inherent magnetic field influence on corrosion resistance of $\mathrm{Nd}-\mathrm{Fe}-\mathrm{B}$ permanent magnets
}

\begin{abstract}
V. P. Tarasov, Professor, Head of the Department of Non-Ferrous Metals and Gold ${ }^{1}$,
E. S. Gorelikov, Deputy Director of Engineering Center and Industrial Technology ${ }^{1}$

A. V. Kutepov, Chief Engineer of Engineering Center and Industrial Technology ${ }^{1}$

o. V. Khokhlova, Assistant of Department of Non-Ferrous Metals and Gold ${ }^{1}$,

e-mail: hohlova.oksana.v@gmail.com
\end{abstract}

${ }^{1}$ National University of Science and Technology "MISiS", Moscow, Russia.

\begin{abstract}
Nowadays permanent magnets of $\mathrm{Nd}-\mathrm{Fe}-\mathrm{B}$ system are widely used in various branches of production. The trend has been toward increase of the world consumption of the magnets in the making of advanced technology gadgets (smartphones, navigators, television sets, and computers). However, this magnet material can not be always applied in the special-purpose devices because of its low corrosion resistance and poor temperature stability. To elongate service life of the magnets it is necessary to deposit a protective coating based on nickel, zinc, copper as well as on the combination of other substances (phosphate, epoxy resin).

The given paper is dedicated to the results of implemented comparative research of corrosion resistance of permanent magnets made of magnetically hard material based on $\mathrm{Nd}-\mathrm{Fe}-\mathrm{B}$ alloy both with metallic anticorrosive coat and without it in a magnetized and non-magnetized state.

It has been found that the inherent magnetization influence on the corrosion resistance of $\mathrm{PM}$ made of $\mathrm{Nd}-\mathrm{Fe}-\mathrm{B}$ $\mathrm{MHM}$ both with metallic anticorrosive coat and without it are of an opposite nature. The corrosion resistance of the samples without coating in the magnetized state has increased by $12 \%$. At the same time, the corrosion resistance of $\mathrm{Zn}$ - and $\mathrm{Ni}$-coated samples in the magnetized state has decreased by $40-45 \%$. It is determined that the coating-free magnets are better to be stored and transported in the magnetized condition while the magnets protected by metallic anticorrosive coats need to be stored in the non-magnetized condition.

Key words: rare-earth elements, permanent magnets, corrosion resistance, anticorrosive coat, magnetization, magnetic field

DOI: $10.17580 / \mathrm{nfm} .2018 .02 .04$
\end{abstract}

\section{Introduction}

A $\mathrm{S}$ it is known, high-performance magnetically hard materials (MHM) based on $\mathrm{Nd}-\mathrm{Fe}-\mathrm{B}$ alloy are characterized by low resistance to corrosion [1-2]. It is one of their main imperfections along with poor temperature stability [3-4]. Therefore, vari- ous anticorrosive coats are used to elongate service life of permanent magnets (PM) made of the above mentioned materials [5-6].

For the most part, different metals (Ni, $\mathrm{Zn}, \mathrm{Al}$, etc.) are used as a material of anticorrosive coats, being deposited by galvanic or another method [7]. 